\title{
Impact Of Organizational Justice On Employee Dissent In Higher Education Sector Of Pakistan: A Women's Perspective
}

\author{
Omar Ahmed Shaikh \\ Karachi University Business School \\ University of Karachi \\ Syed Shabib-ul-Hasan \\ Hamdard University \\ Karachi
}

\begin{abstract}
This study examined the impact of organizational justice on employee dissent from the perspective of female employees. Participants were 210 full time female teachers working in several universities across Sindh Pakistan. Scope of this research shall encompass the justice and dissent perceptions of female teachers in these universities. This research uses a quantitative method by using survey, and proportionate stratified random sampling technique was used to collect data. Multiple regression analysis was used in order to explore the relationship between variables. Results indicated that perceptions of interactional and distributive justice are negatively associated with displaced dissent, whereas procedural justice is not related with displaced dissent. Interactional justice proved to be the strongest predictor of displaced dissent followed by distributive justice. Perceptions of organizational justice were not related to latent or articulated dissent. Future research should also focus on explaining occurrence of dissent in various organizational settings such as service or production based organizations.
\end{abstract}

Keywords: Organizational Justice, Employee Dissent, Injustice, Employee Responses, Gender.

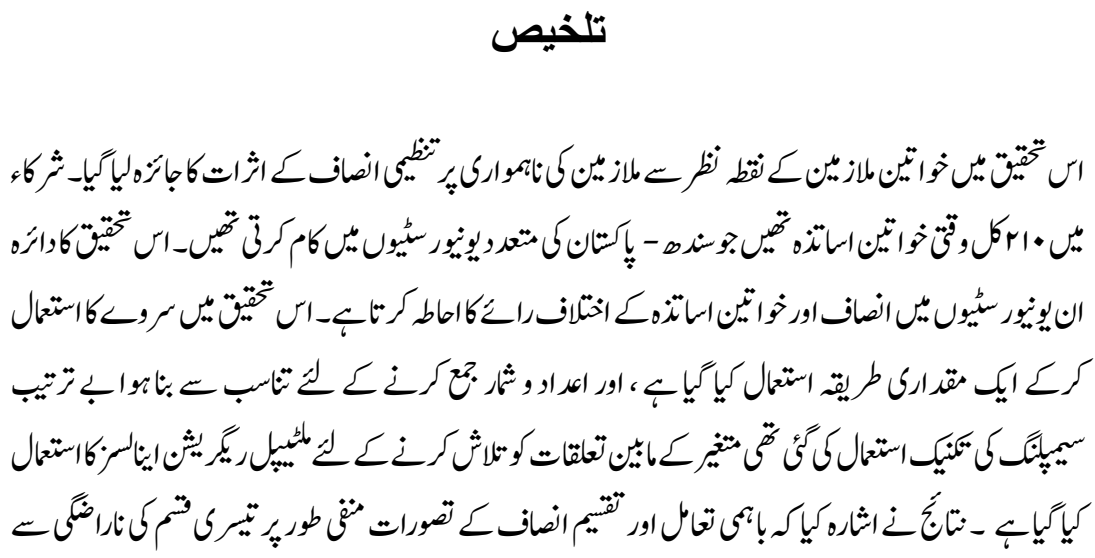




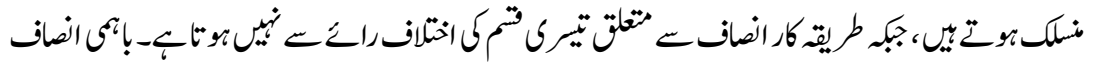

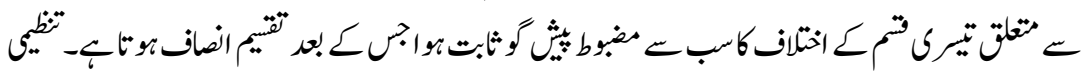

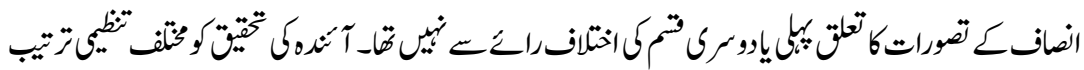

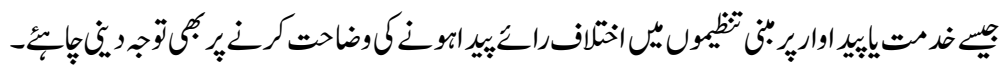

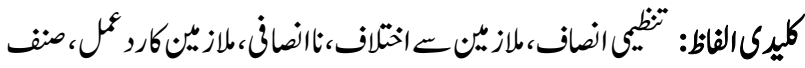

\section{Introduction}

Organizational justice is an integral part of any organization which plays its role to shape norms and values related to several affairs such as rewards, relationships or procedures (Karam et al., 2019). Organizational justice remained a subject of interest for many scholars as they studied life cycle of an employee in an organization starting from his/her entry till their exit (Lazar, Zinger and Lachterman, 2007). Organizational justice includes three dimensions i.e. procedural, distributive and interactional. Distributive justice refers to the distribution of resources; procedural justice refers to the procedures that are being used in organizations for the distribution of resources whereas interactional justice explores the way in which supervisors treat their subordinates (Greenberg, 2002). In general, it helps achieving four objectives. First, it helps controlling behaviours as it helps diminish uncertainty in unstable circumstances (Colquitt and Rodell, 2011). Second, it shapes attitudes, feelings, values and behaviours (Totawar \& Nambudiri, 2014). Third, it shapes the procedures to regulate outcomes (Avery and Quinones, 2002). Finally, it supports employees discovering variables such as employee affect, self-concept and self-regard (Cropanzano, Goldman \& Folger, 2003). Researchers have found that perceptions of organizational justice form behaviours of employees which may be positive or negative (Rubino, et al., 2018). OCB (organizational citizenship behaviour), organizational commitment, job performance and job satisfaction are some of the positive results of organizational justice whereas theft, retaliation and job burnout are considered as some of the negative behaviours as a result of organizational injustice (Zapata-Phelan et al., 2009). As the consequence of an undesirable event in organizations, employees usually impart their difference and disappointment to their supervisors, peers, and relatives or friends in the form of organizational dissent (Kassing \& Armstrong, 2002). Looking at the reasons with respect to why and to whom workers convey disagreement has been a matter of interest for many researchers (De Ruiter, Schalk $\&$ Blomme, 2016). However, very few researches have focused on "what women want" while they are working in organizations (Ansari et al., 2016).

This lack of information regarding women's perceptions of justice and dissent, in particular culture of Pakistan, itself becomes an obstacle for employers to deal 
fairly with the issues of working women. Lack of awareness regarding such matter also hinders employers' ability to come up with innovative policies to foster a culture where women are treated with dignity and respect, not in a way as 'policy makers' think but in a way that women deserve; a fair way. Scholars around the world continue to report that such approaches lead to absenteeism, non productive work behaviour and high turnover among female employees which consequently turns into a gender specific glass ceiling (Ensher et al., 2001).

In this study the author intends to collect data regarding the perceptions of injustice in organizations and consequential response from the perspective of a female employee. The data will then be analysed to find out which dimension of justice most severely affects the dissent behaviour of a female employee. This study will supplement the developing body of research by looking at organizational dissent resulting from the perceptions of injustice happening in higher education sector of Pakistan. Hence the objective of this study is to explore this phenomenon so that in light of the conclusions, work place policies and practices may be revised in order to make them more convenient for both genders, especially for women. Following is an overview of existing literature in the field of employee dissent and organizational justice.

\section{Review of Literature}

\section{Organizational Justice}

As many scholars suggest that the perceptions of organizational justice have a huge impact on many outcomes of an employee including behaviours such as organizational citizenship behavior, job satisfaction, job performance or employee dissent (Masterson et al., 2000; Ball, Trevino, \& Sims, 1994; Karam et al., 2019). Byrne and Cropanzano (2001) explain organizational justice as the study of impartiality or fair treatment in organizations. There are many definitions of organizational justice such as Greenberg's (1993) four factor model of organizational justice which explains that there are four dimensions of organizational justice namely Procedural Justice, Distributive Justice and Interactional Justice (interpersonal and informational justice). Every dimension, as explained by Greenberg (1993), provides a unique opportunity to see justice as an initiator of various behaviours (Musringudin, Akbar \& Karnati, 2017). These behaviours may include positive (in case employee perceive fairness) or negative behaviours (in case employees feel that they are not being treated fairly) (Colquitt, 2001). This study will use the same definition of organizational justice which is regarded as one of the most commonly used definitions by Colquitt (2001). Other scholars such as Palaiologos et al. (2011) also regard this definition and suggest that most humans are primarily interested in three factor related to fair treatment. First, distributive justice second is procedural justice and the third one is interactional justice. 
Distributive justice refers to the perceptions of the people about the fairness of rewards that are distributed by the competent authorities within the organization (Greenberg, 1986). These rewards may include various kinds of monetary and nonmonetary benefits such as salary, commissions, bonuses etc. (Wenzel, 2004). Lim, \& Loosemore (2017) state that the term fairness is more subjective than objective hence distributive justice is something that happens not as a result of reality but as a result of perception. For example, if workers are getting what they accept to be a decent reward, they are satisfied; however in the event that they don't get what they figure they ought to get, they begin showing dissent. Second type of justice is procedural where employees perceive the process of distributing rewards as fair or unfair (Folger \& Cropanzano, 1998). The third type is interactional justice where employees start perceiving about the way they are being treated by their supervisors (Crow et al., 2012). If employees feel that there is organizational justice in organization, they tend to behave in a civilised manner but if they feel injustice their behaviours tend to turn out in a more negative way (Nix \& Wolfe, 2016).

Generally, literature suggests that the qualities that women and men place on different working environment such as rewards, compensation and appreciation (Ross \& Mirowsky, 1996) are similar. Women and men likewise have comparative degrees of job satisfaction and commitment, as well as work attitudes (Mottaz, 1988; Mueller \& Wallace, 1996). However some scholars disagree (Jepsen \& Rodwell, 2012; Ramamoorthy \& Flood, 2004). They contended that women place more value on equity and decency of working environment methods than do men, while men esteem impartial working rewards as compared to women (Gilligan, 1993). Some other studies also indicate that women tend to react (dissent) differently than men when perceptions of injustice are on the higher side (Warner, 2013). No previous researches in the area of organizations justice perceptions of women were found in context of Pakistani education sector. The reason because this research was expected to produce different results is because according to gender approach, socialization process may vary from country to country and consequently resulting in fundamental personality differences, therefore expectations of women may also vary from their organizations. It is also assumed that sometimes socialization route cause females to value relationships resulting in them to expect good work environment as compared to fairness in procedures or distribution whereas men would expect more of good pay rather than having good relations in first place (Gilligan 1993; Kahn et al. 1980).

\section{Organizational Dissent}

Dissent is considered as a reaction of a worker resulted because of perceived injustice (Kassing, 1998) or a consequence of disappointment with current circumstance. Bailey (2001) states that this sort of conduct or reaction is normally negative and isn't advantageous for the profitability of an organization. Kassing (2011) states that some unacceptable types of employee dissent incorporate 
whistle blowing where one decides to communicate their contradictions before regulatory authorities or media.

Among all researchers, Kassing (1997) has a significant commitment in investigating the expression employee dissent. Kassing (1998) additionally proposed that there are three kinds of Dissent, articulated, latent and displaced dissent. This research will utilize the dimensions established by Kassing (1998) to characterize employee dissent as a consequence of organizational. The term explained articulated dissent as conduct of the individuals when they transparently and straightforwardly begin imparting their concerns regarding organizational policies before the individuals who are influential inside the organization (Kassing, 1997). Individuals communicating Latent Dissent convey such fears before the individuals who are not very influential can't have any kind of effect in existing situation Displaced dissent is a third way utilizing which individuals commonly communicate their grief in regards to the strategies and practices of organization before outsiders, for example, friends or family. Literature suggests that socialization process of a culture tends to form behaviour of women which they also practice in their organizations (Smith, Smits and Hoy, 1998). Therefore women tend to display dissent in a different way than men who usually become more involved in politics and latent dissent.

Organizational justice influences this behaviour of dissent in many ways. Scholars argue that one of those variables that mediate this relationship is "gender". This study was conducted in 25 higher education institutions of the province of Sindh, Pakistan. Rationale of this study is the fact that women in Pakistan are sometimes reluctant to work in any kind of office environment due to several issues one of which may be discriminatory practices (Bukhari \& Ramzan, 2013). Education institutions, especially higher education institutes, are no exception. The conclusions of this research shall help policy makers to develop such practices that would help identify and eliminate those practices (from the perspective of organizational justice) that are causing inconvenience for women. This shall lead to a working environment that is one more step towards equity and an environment motivating for women and they would be able to contribute in the process of building nation as teachers.

\section{Theoretical Foundation}

Besides responding negatively to bosses and the organization, as equity theory (Adams, 1965) and related research (Hubbell and Chory, 2005) propose, workers may react to organizational injustice by showing their dissent. Individuals may express their contradictory opinions to supervisors in order to impact change and to colleagues and/or people outside organization (e.g., relatives) to vent disappointment and seek emotional support, and in light of the fact that they might be reluctant to stand up to their bosses inspired by a paranoid fear of termination. 
Adam's equity theory (1965) helps understanding the foundations of employee dissent as a consequence of perceived organizational injustice. The theory explains that employees want to maintain a justified relationship between their inputs and outputs and if they perceive that their input output ration is less than their peers, they perceive injustice which results in negative behaviours, one example of which is employee dissent (Bell \& Martin, 2012).

This research attempts to investigate teachers working in universities of Pakistan, across the province of Sindh, and their tendency to dissent before their managers, peers, and to their informal community companions outside of their organizations about distributive, procedural, and interactional injustice.

In view of the previously mentioned research and reasoning, the following hypothesis and research question were progressed.

$\mathrm{H}$ : tendency of women to engage in dissent is negatively associated with organizational justice

$\mathrm{H}(\mathrm{a})$ : tendency of women to engage in dissent is negatively associated with procedural justice.

$\mathrm{H}(\mathrm{b})$ : tendency of women to engage in dissent is negatively associated with distributive justice.

$\mathrm{H}(\mathrm{c})$ : tendency of women to engage in dissent is negatively associated with interactional justice.

RQ: Which dimension of organizational justice will be the most grounded indicator of each type of employee dissent?

\section{Methodology}

To examine and validate the empirical relationship between the variables, this research uses a quantitative (positivist) method by using survey and proportionate stratified random sampling technique was adopted to collect data. Reason for using proportionate stratified random sampling is this that the population is divided into four groups and appropriate number of responses are required from each stratum. A sample size of 210 female teachers was used. The universe of this study would be the working women across Pakistan.

Population for this study comes from 25 universities across the province of Sindh. These are the universities that are chartered by Higher Education Institute (HEC) of Pakistan as $\mathrm{PhD}$ granting institutes, they are also chartered by government of Sindh and located in the province of Sindh. The population of this study is placed in four categories i.e. lecturers, Assistant Professors, Associate Professor and Professors.

The Survey questionnaire was designed based on previously developed and tested scales. This survey questionnaire had a total of 44 items out of which 20 items were intended to obtain scores about independent variable which was 
organizational justice, 24 items were intended to collect responses to obtain scores related to dependent variable which was employee dissent. The data was gathered from 17 universities of Karachi, 3 universities in Jamshoro, 2 in Hyderabad and 1 in each city of Khairpur, Nawabshah and Sukkur using self-report scales for independent and dependent variables.

Participants were asked to fill in a self-report questionnaire covering measures of organizational justice and employee dissent along with items assessing demographic characteristics. Recognized scale developed by Jason A. Colquitt (2001) was used to measure the dimension of organizational justice whereas employee dissent was measured using the scale developed by Jeffrey Kassing (1998).

\section{Results}

The hypothesis suggested that employees have a tendency to engage in dissent as a result of perceived unfairness and the research question is concerned about which one of the justice dimensions has the biggest impact on employee dissent. Three multiple regression were employed, one for each dimension of dissent to test the hypothesis and answer research question. The reliabilities and descriptive for all scales are presented in Table 1 .

Table: 1

Reliabilities, means and standard deviations

\begin{tabular}{|l|l|l|l|}
\hline & $\alpha$ & $\mathrm{M}$ & SD \\
\hline Procedural Justice & .740 & 22.5 & 4.20 \\
\hline Distributive Justice & .869 & 14.38 & 3.32 \\
\hline Interactional Justice & .889 & 33.14 & 6.23 \\
\hline Articulated Dissent & .708 & 30.53 & 4.79 \\
\hline Latent Dissent & .716 & 26.40 & 4.23 \\
\hline Displaced Dissent & .740 & 17.01 & 3.95 \\
\hline
\end{tabular}

Results indicated that variables of Organizational Justice predicted Displaced Dissent, $\mathrm{F}(3,206)=7.561, \mathrm{R} 2=.099, \mathrm{P}<.01(.000)$ but not latent dissent, $\mathrm{F}(3,206)$ $=1.604, \mathrm{R} 2=.023, \mathrm{P}>.05(.190)$ or articulated dissent $\mathrm{F}(3,206)=.459, \mathrm{R} 2=.007$, $\mathrm{P}>.05$ (.711). Therefore our hypothesis was partially supported and interactional justice is the strongest predictor of displaced dissent, $\beta=-0.52 *$, followed by distributive justice $\beta=-0.48 *$. Procedural justice, $\beta=.009$, did not predict displaced dissent. Results for multiple regression analysis are presented in table 2. 
Table: 2

Results for multiple regression analysis

\begin{tabular}{|l|c|c|c|}
\hline \multirow{2}{*}{} & $\begin{array}{c}\text { Articulated } \\
\text { Dissent }\end{array}$ & Latent Dissent & Displaced Dissent \\
\cline { 2 - 4 } & $\beta$ & $\beta$ & $\beta$ \\
\hline Procedural Justice & 0.019 & .159 & 0.09 \\
\hline Distributive Justice & -0.061 & .126 & $-.48^{*}$ \\
\hline Interactional Justice & 0.086 & .130 & $-.52^{*}$ \\
\hline & $\mathrm{F}(3,206)=.459$ & $\mathrm{~F}(3,206)=1.604$ & $\mathrm{~F}(3,206)=7.561^{*}$ \\
\hline & $\mathrm{R}^{2}=.007$ & $\mathrm{R}^{2}=.110$ & $\mathrm{R}^{2}=.099$ \\
\hline & \multicolumn{3}{|l}{} \\
\hline
\end{tabular}

\section{Discussion}

Human capital plays an important role in the development of an economy. This human capital owns a big favour to higher education institutes who are responsible for producing researchers, scholars, good citizens, businessmen etc. Therefore, higher education institutes in any country play a very vital role in helping their economies grow and sustain. Since higher education is extremely important for the social and economic prosperity of a country, employees working in higher education system must also observe such a conduct that is true reflection of an inspirational figure. Yet, we don't see much of a debate going particularly in context "how to treat women fairly". As research suggests, women are likely to express disagreement in a different way than men and they are also likely to perceive justice in a different manner (Ansari et al., 2016). Therefore, definition of fair treatment may not be the same for women as it is for men. Increased participation of women in workforce has also highlighted the responsibility of employers to deal with their female workers in a more respectful and civilized manner as it is not only their responsibility but a social and ethical obligation as well.

Analysis of results revealed that females are likely to express disagreement or dissent before their family, friends or loved ones outside their organizations if they perceive distribution of rewards to be unfair and the superiors who arrived at the distribution decisions clearly and openly explain everything to them but in a disrespectful manner. However, perceptions of justice are found to be unrelated with latent or articulated dissent.

The connections that developed between organizational justice and displaced dissent might be explained by individuals' propensity to relate their outcomes, for example, their compensation plans with those of their colleagues or peers. In accordance with equity theory (Adams, 1965), individuals tend to form their view of organizational justice by contrasting the rewards they are receiving with someone else within the same organization who holds a comparative, if not indistinguishable, position. Taking into account that employees express their disappointment about injustice in front of those who are close to their hearts is a 
usual human behaviour. The outcome of the research reinforces this supposition. Also, organizational justice and displaced dissent may have been most firmly related in light of the fact that communicating contradiction to such people might be the most quick and advantageous methods for imparting emotions. While perceptions of interactional justice and distributive justice are related with displaced dissent, the perceptions of procedural justice are not. These outcomes are unexpected given that procedural justice has frequently been a stronger and stable indicator than different kinds of organizational justice (Colquitt et al., 2001). This may be considered as one of the dimensions that is consistent throughout the literature, however in case of women it becomes insignificant. The results however are consistent with the research of many scholars who suggest that women are more inclined to receive dignified treatment than men who would like to receive better pay than an environment which provides dignified and respectful treatment. A close look at the characteristics of the population of study revealed another facet. The population consisted of all professionals and highly educated individuals i.e. lecturers, assistant professors, associate professors and professors which may also be considered as one of the reasons why they might be more focused on receiving better treatment followed by being rewarded for their services whereas procedures used for receiving rewards may not be much of a concern for these people. This concept is very well illustrated in the Need theory of David McClelland (1960).

The absence of findings with respect to organizational justice and latent dissent might be clarified by a few factors. One reason that may explain no relation between organizational justice and latent dissent is this that women feel comfortable to talk to anyone in an organizational setting that they perceive as 'fair'; hence express latent dissent. A research conducted by Guney (2006) suggested that Pakistani women are usually seen as "incompetent" in their organizations not only by their male managers but also even by female managers. Whereas in an environment where they feel injustice is being practiced, they are not likely to express their dissent especially in front those who they think may be responsible for injustice (Ozsahin \& Yurur, 2019).

As far as articulated dissent is considered, it may not be identified with organizational justice in light of the fact that women professionals, such as teachers, may not only feel it as improper to complaint about work issues in front of their supervisors, but also of being labelled as someone trying to show "masculine character" Guney (2006), or even a fear of being terminated. In contrast to this specific study, some scholars suggest that individuals may wish to keep their organizational and home lives distinct and only express their disagreement in front of their colleagues and would not be very much interested in disclosing the details of injustice in front of their friends and family (McCroskey et al., 2004). However in this case it was completely opposite and women tend to complain in front of their friends and family more than they do complain in front of their supervisors and colleagues. 
As for procedural justice which is not related to any one of the dissent dimensions, a possible explanation could be the fact that friends and family may they may wish to know further details regarding how policies are made, who makes them, how they are implemented etc. The failure to witness a connection between organizational justice and articulated dissent is similar to the effect where many researches showed that the articulated dissent frequently fails to produce assumed hypothesis (Kassing \& Avtgis, 1999).

\section{Conclusions and Recommendations}

As a result of analysing perceptions of organizational justice among females in educations sector of Pakistan and resulting behaviours, following conclusion can be made. First, female faculty members at different universities generally choose to express their disagreement in front of their friends and family rather than their colleagues or supervisors. It is also found that these educators are more concerned regarding self-respect rather than the distribution or procedures within their organizations. These conclusions may also be used as a guideline for managers or policy makers in such organizations to look at their practices and policies for a second time and try to maintain such a balance between that not only fosters an environment of positive perceptions of organizational justice but also cultivates a culture where women are treated and paid in a better way than before.

\section{Limitation and Further Research}

In spite of the fact that this examination gives knowledge into the connections among organizational justice and employee dissent from a female's perspective, it has a few limitations. First, the research was conducted purely in an educational setting where work environment, timings, and interaction with peers occur in a completely different way than other service or production based environments. Secondly, the population consisted of highly homogenous and qualified subjects who may perceive fairness in a completely different way than a usual employee in any other organization. Therefore it is highly recommended that further research must be carried out in order to compare and contrast various populations in different organizations.

\section{References}

Adams, J. S. (1965). Inequity in Social Exchange. Advances in Experimental Social Psychology, vol.2, pp.267-299.

Ansari, N., Moazzam, A., Jabeen, N., \& Salman, Y. (2016). Gender and Perceptions of Organizational Justice: A Study of University of the Punjab. Pakistan Journal of Women's Studies, vol.23:1, pp.45-63.

Avery, D. R. \& Quiñones, M. A. (2002). Disentangling the Effects of Voice: The Incremental Roles of Opportunity, Behavior and Instrumentality in Predicting Procedural Fairness. Journal of Applied Psychology, vol.87:1, p.81. 
Ball, G. A., Trevino, L. K. \& Sims Jr, H. P. (1994). Just and Unjust Punishment: Influences on Subordinate Performance and Citizenship. Academy of Management Journal, vol.37:2, pp.299-322.

Bailey, K. D. (2001). Towards Unifying Science: Applying Concepts Across Disciplinary Boundaries. Systems Research and Behavioral Science: The Official Journal of the International Federation for Systems Research, vol.18:1, pp.41-62.

Bell, R. \& Martin, J. (2012). The Relevance of Scientific Management and Equity Theory in Everyday Managerial Communication Situations. Journal of Management Policy and Practice, vol.13:3, pp.106-115.

Bukhari, F. Y. \& Ramzan, M. (2013). Gender Discrimination: A Myth or Truth Women Status in Pakistan. Journal of Business and Management, vol.8:2, pp.88-97.

Byrne, Z. S. \& Cropanzano, R. (2001). The History of Organizational Justice: The Founders Speak. Justice in the Workplace: From Theory to Practice, vol.2:1, pp.3-26.

Colquitt, J. A. \& Rodell, J. B. (2011). Justice, Trust and Trustworthiness: A Longitudinal Analysis Integrating Three Theoretical Perspectives. Academy of Management Journal, vol.54:6, pp.1183-1206.

Colquitt, J. A. (2001). On the Dimensionality of Organizational Justice: A Construct Validation of a Measure. Journal of Applied Psychology, vol.86:3, p.386.

Cropanzano, R., Goldman, B. \& Folger, R. (2003). Deontic Justice: The Role of Moral Principles in Workplace Fairness. Journal of Organizational Behavior: The International Journal of Industrial, Occupational and Organizational Psychology and Behavior, vol.24:8, pp.1019-1024.

Crow, M. S., Lee, C. B. \& Joo, J. J. (2012). Organizational Justice and Organizational Commitment among South Korean Police Officers: An Investigation of Job Satisfaction as a Mediator. Policing: An International Journal of Police Strategies \& Management, vol.35:2, pp.402-423.

De Ruiter, M., Schalk, R. \& Blomme, R. J. (2016). Manager Responses to Employee Dissent about Psychological Contract Breach: A Dyadic Process Approach. Management Communication Quarterly, vol.30:2, pp.188-217.

Ensher, E. A., Grant $\square$ Vallone, E. J. \& Donaldson, S. I. (2001). Effects of Perceived Discrimination on Job Satisfaction, Organizational Commitment, Organizational Citizenship Behavior and Grievances. Human Resource Development Quarterly, vol.12:1, pp.53-72. 
Folger, R. and Cropanzano, R.S. (1998), Organizational Justice and Human Resource Management. Thousand Oaks, CA: SAGE Publications, Inc.

Greenberg, J. (1986). Determinants of Perceived Fairness of Performance Evaluations. Journal of Applied Psychology, vol.71:2, pp.340-342.

Greenberg, J., Baron, R. A. \& Grover, R. A. (1993). Behavior in Organizations: Understanding and Managing the Human Side of Work. Boston: Allyn and Bacon.

Greenberg, J. (2002). Advances in Organizational Justice. Stanford, California: Stanford University Press

Gilligan, C. (1993). In a Different Voice: Psychological Theory and Women's Development. Cambridge, Massachusett: Harvard University Press.

Guney, S., Gohar, R., Akınc1, S. K. \& Akınc1, M. M. (2006). Attitudes toward Women Managers in Turkey and Pakistan. Journal of International Women's Studies, vol.8:1, pp.194-211.

Hubbell, A. P. \& Chory $\square$ Assad, R. M. (2005). Motivating Factors: Perceptions of Justice and their Relationship with Managerial and Organizational Trust. Communication Studies, vol.56:1, pp.47-70.

Jepsen, D. M. \& Rodwell, J. (2012). Female Perceptions of Organizational Justice. Gender, Work \& Organization, vol.19:6, pp.723-740.

Kahn, A., Krulewitz, J. E., O'Leary, V. E. \& Lamm, H. (1980). Equity and Equality: Male and Female Means to a Just End. Basic and Applied Social Psychology, vol.1:2, pp.173-197.

Karam, E. P., Hu, J., Davison, R. B., Juravich, M., Nahrgang, J. D., Humphrey, S. E. \& Scott DeRue, D. (2019). Illuminating the 'face' of justice: A Meta $\square$ Analytic Examination of Leadership and Organizational Justice. Journal of Management Studies, vol.56:1, pp.134-171.

Kassing, J. W. (1998). Development and Validation of the Organizational Dissent Scale. Management Communication Quarterly, vol.12:2, pp.183-229.

Kassing, J. W. (2011). Dissent in Organizations. Cambridge: Polity Press.

Kassing, J. W. (1997). Articulating, Antagonizing and Displacing: A Model of Employee Dissent. Communication Studies, vol.48:4, pp.311-332.

Kassing, J. W. \& Armstrong, T. A. (2002). Someone's Going to Hear About This: Examining the Association between Dissent-Triggering Events and Employees' Dissent Expression. Management Communication Quarterly, vol.16:1, pp.39-65. 
Kassing, J. W. \& Avtgis, T. A. (1999). Examining the Relationship between Organizational Dissent and Aggressive Communication. Management Communication Quarterly, vol.13:1, pp.100-115.

Lazar, A., Zinger, A. \& Lachterman, B. (2007). The Influence of Pre-Feedback Selection Justice on Perceptions of Overall Procedural Justice and Organizational Attractiveness in a Real-Life Selection Procedure. European Journal of Work and Organizational Psychology, vol.16:1, pp.94-109.

Lim, B. T. \& Loosemore, M. (2017). The Effect of Inter-Organizational Justice Perceptions on Organizational Citizenship Behaviors in Construction Projects. International Journal of Project Management, vol.35:2, pp.95-106.

Masterson, S. S., Lewis, K., Goldman, B. M. \& Taylor, M. S. (2000). Integrating Justice and Social Exchange: The Differing Effects of Fair Procedures and Treatment on Work Relationships. Academy of Management journal, vol.43:4, pp.738-748.

McClelland, D. C. (1960). The Achieving Society. Princeton, New Jersey: D. Van Norstrand Company.

McCroskey, J. C., Richmond, V. P., Johnson, A. D. \& Smith, H. T. (2004). Organizational Orientations Theory and Measurement: Development of Measures and Preliminary Investigations. Communication Quarterly, vol.52:1, pp.1-14.

Mottaz, C. J. (1988). Work Satisfaction among Hospital Nurses. Journal of Healthcare Management, vol.33:1, p.57.

Mueller, C. W., \& Wallace, J. E. (1996). Justice and the Paradox of the Contented Female Worker. Social Psychology Quarterly, vol. 59:4, pp.338-349.

Musringudin, M., Akbar, M. \& Karnati, N. (2017). The Effect of Organizational Justice, Job Satisfaction and Organizational Commitment on Organizational Citizenship Behavior (OCB) of the Principles. IjerIndonesian Journal of Educational Review, vol.4:2, pp.155-165.

Nix, J. \& Wolfe, S. E. (2016). Sensitivity to the Ferguson Effect: The Role of Managerial Organizational Justice. Journal of Criminal Justice, vol.47, pp.12-20.

Ozsahin, M. \& Yurur, S. (2019). Does Organizational Justice Increase Or Decrease Organizational Dissent? Research Journal of Business and Management, vol.6:1, pp.1-8. 
Palaiologos, A., Papazekos, P. \& Panayotopoulou, L. (2011). Organizational Justice and Employee Satisfaction in Performance Appraisal. Journal of European Industrial Training, vol.35:8, pp.826-840.

Ramamoorthy, N. \& Flood, P. C. (2004). Gender and Employee Attitudes: The Role of Organizational Justice Perceptions. British Journal of Management, vol.15:3, pp.247-258.

Ross, C. E. \& Mirowsky, J. (1996). Economic and Interpersonal Work Rewards: Subjective Utilities of Men's and Women's Compensation. Social Forces, vol.75:1, pp.223-245.

Rubino, C., Avery, D. R., McKay, P. F., Moore, B. L., Wilson, D. C., Van Driel, M. S. \& McDonald, D. P. (2018). And Justice for All: How Organizational Justice Climate Deters Sexual Harassment. Personnel Psychology, vol.71:4, pp.519-544.

Smith, P. L., Smits, S. J. \& Hoy, F. (1998). Employee Work Attitudes: The Subtle Influence of Gender. Human Relations, vol.51:5, pp.649-666.

Totawar, A. K. \& Nambudiri, R. (2014). Can Fairness Explain Satisfaction? Mediation of Quality of Work Life (QWL) in the Influence of Organizational Justice on Job Satisfaction. South Asian Journal of Management, vol.21:2, pp.101-122.

Warner, M. (2013). Managing Across Diverse Cultures in East Asia: Issues and Challenges in a Changing Globalized World. London: Routledge.

Wenzel, M. (2004). An Analysis of Norm Processes in Tax Compliance. Journal of Economic Psychology, vol.25:2, pp.213-228.

Zapata-Phelan, C. P., Colquitt, J. A., Scott, B. A. \& Livingston, B. (2009). Procedural Justice, Interactional Justice and Task Performance: The Mediating Role of Intrinsic Motivation. Organizational Behavior and Human Decision Processes, vol.108:1, pp.93-105.

Omar Ahmed Shaikh is Lecturer in the Karachi University Business School, University of Karachi, Karachi, Pakistan.

Prof. Dr. Syed Shabib-ul-Hasan is Vice Chancellor of Hamdard University, Karachi, Pakistan. 